\title{
Experimental Study of Laser Assisted Drilling and Parameters Analysis
}

\author{
Yingpin WANG*, Gong ZHANG, Lei ZHENG, Yunpeng REN, Olaf Eichstaedt, \\ Xianshuai CHEN \\ Precision Engineering Research Center, Guangzhou Institute of Advanced Technology, Chinese Academy of \\ Sciences, Guangzhou 511458, China
}

\begin{abstract}
Drilling holes in the key parts of automotive transmissions (e.g. the crank shaft) can be difficult and time consuming. For this reason, laser assisted drilling is proposed to increase processing speed and reduce wear of tools. In this paper, an experimental study is used to investigate optimum processing parameters of laser assisted drilling in different materials relevant for the automotive industry, such as 45 steel , 40Cr steel, QT600 steel and stainless steel 430L. The experimental results show that laser assisted drilling offers process improvements and are provided with a high application value.
\end{abstract}

KEYWORD: Laser assisted drilling; Experimental study; Automotive industry; Power train components

\section{INTRODUCTION}

The key parts of automobile, such as gear shaft, crank shaft, balance shaft etc., usually employ forged work-piece or hardened materials, and as a consequence the high surface hardness makes traditional drilling processes time consuming and difficult, e.g. the temperature can increase quickly and the wear of the tools is considerable [1]. This is especially true for drilling hole which are not perpendicular to the parts surface. When thin tools are required, it will be difficult to drill at the intended location and the tool may easily break. To overcome these problems, laser assisted drilling has been proposed. Laser assisted drilling belongs to the group of laser assisted machining, which means a laser is used to locally heat the work piece. In the case of laser assisted drilling, a small area is heated under the tip of the drill, the increased temperature will soften the work-piece, and reduce cutting resistance, thus achieving higher material-removal rates, and offering to precisely control the machined geometry and increase tool life, thereby significantly reducing cycle time for both operator and machine.

Recently, innovations in laser assisted machining have been made in laser assisted turning and laser assisted milling. Shin Y.C.[2-5] of Purdue University built a 3D finite element analysis (FEA) model of laser assisted machining, investigated laser and cutting parameters and their influence on work piece temperature, cutting force and wear of tools while turning Si3N4 ceramics. Tian Y.G. [6] applied laser assisted burnishing (LAB) instead conventional burnishing experiments with MP35N and AISI 4140, to evaluate the effect of laser power on the polishing process. His experiments show that LAB can produce a much better surface finish, higher surface hardness then conventional methods and also offers reduced wear on the tools.LEE C.M. [7-9] applying FEA method to predict the temperature distribution of inclined laser preheating assisted machining and conducted one-axis manipulator with a CNC machining center. Budong Yang [10] of Kansas State University built a laser assisted milling system (LAM) to study the machinability of Si3N4 ceramic. University of Aachen's Fraunhofer Institute for Laser Technology (ILT) have done a lot of researches on laser assisted machining and designed some LAM equipments[11]. In China, many scholars have engaged in research about LAM, such as Wang Huiyi [12] who uses finite element analysis (FEA) to predict the temperature field of 45 steel during laser assisted milling. Research of Wu Jian [13] focuses on hardening and phase transformation in laser assisted machining, and analyses the influence of several parameters. YAN Cuo [14] established a quasi-steady state heat conduction model for laser assisted machining of hot-sintered $\mathrm{Al} 2 \mathrm{O} 3$ ceramics using the finite difference method (FDM) to calculate the temperature distribution in the workpiece.

However, not much research are focused on laser assisted drilling (LAD). Only Tien-Chien Jen[15] of University of Wisconsin-Madison did apply annular laser spot to improve drilling performance. He also used finite element analysis (FEA) to simulate the 
temperature field during laser assisted machining. In this paper, we describe a experimental platform to investigate LAD, study the parameters which are important to laser assisted drilling, and obtain optimum parameters for different materials to illustrate the effect of laser assisted drilling.

\section{THEORY}

Laser assisted drilling is an advance manufacture technology, it applies laser to heat and soften the work local. By doing this, the precision and efficiency can be both improved [14]. The working principle shows in Fig.1. $\mathrm{n}$ is rev of drilling tool, $\theta$ is the angle of laser light with tool's center line.

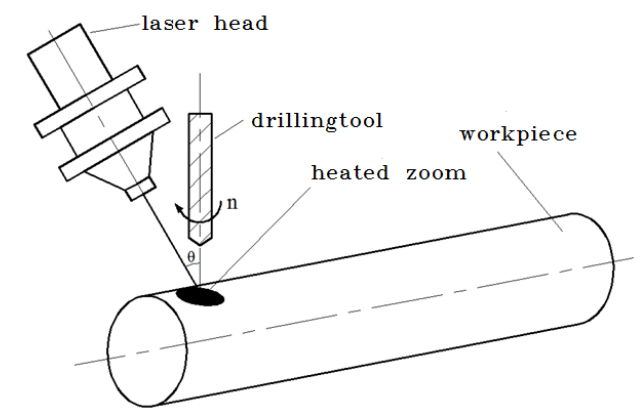

Fig.1 Schematic diagram of laser assisted drilling zone

The heat transfer equation could be expressed as:

$$
\frac{\partial}{\partial x}\left(K(T) \frac{\partial T}{\partial x}\right)+\frac{\partial}{\partial y}\left(K(T) \frac{\partial T}{\partial y}\right)+\frac{\partial}{\partial z}\left(K(T) \frac{\partial T}{\partial z}\right)+g=\rho(T) C_{P}(T) \frac{\partial T}{\partial t}
$$

Where, $K$ is heat transfer coefficient of material, $\rho$ is material density, $C_{p}$ is material specific heat, $g$ is internal heat source of material.

To be brief, it is assumed that:

1. The material heat parameters (as specific heat $C_{p}$, heat transfer coefficient $K$ ) not change with temperature; (is this right? Generally not)

2. All of materials are isotropic;

3. Ignore convection and eradiate heat transfer of the surface on heating;

4. In the whole process, internal heat source $g$ is zero.

From above, the Eq.(1) could be simplified as:

$$
K\left(\frac{\partial^{2} T}{\partial x^{2}}+\frac{\partial^{2} T}{\partial y^{2}}+\frac{\partial^{2} T}{\partial z^{2}}\right)=\rho C_{P} \frac{\partial T}{\partial t}
$$

In heating process, the heat flow density induced by laser is $q$.

$$
q=A * I
$$

Where, $A$ is absorb coefficient of work-piece surface, $I$ is power density of incidence light.

Assuming that laser beam is Gaussian distribution, then the power density distribution $I$ is :

$$
I=\frac{2 P}{\pi r_{b}^{2}} \exp \left(-\frac{2 r^{2}}{r_{b}^{2}}\right)
$$

Where, $P$ is the power of laser, $r_{b}$ is the radius of laser spot, $r$ is distance of the spot center to the goal point.

It can be seen From Fig. 1 that, the laser light incidence angle is not $0^{\circ}$, so the light beam reflect on the work-piece surface is elliptical. Its long radius is $r_{b} / \cos \theta$ and short radius is $r_{b}$, thus the power density distribution $I$ is:

$$
I=\frac{2 P \cos \theta}{\pi r_{b}^{2}} \exp \left(-\frac{2 r^{2} \cos \theta}{r_{b}^{2}}\right)
$$

In laser assisted drilling experiment, the surface layer metal can be heated up and softened rapidly which is beneficial to drilling. From above formula, it can be seen that the less incidence angle $\theta$ is, the bigger power density $I$ will be.

\section{EXPERIMENT SETUP}

Fig.2 shows an overview of the experimental setup. The main components of the setup are an ABB sixaxis robot IBR2400-16, a SPI 200W optical fiber laser, HASS laser head, a bench-type drilling machine, and an infrared thermo-sensor. Workpieces are plates and tubes of $45 \#$ steel, $40 \mathrm{Cr}$, QT600, and stainless steel.430L respectively, Plate dimensions are $100 \times 50 \times 20 \mathrm{~mm}$, tube dimensions are $\varnothing 40 \times 5 \times 200 \mathrm{~mm}$. To establish similar initial conditions, the work-pieces are polished, to remove micro-cracks at the surface, oxide layers, and scratches. The surface is then cleaned with alcohol to remove oil before the experiment. A $3 \mathrm{~mm}$ (hard alloy YG3X) drill is used as drilling tool, the angle of incidence for the laser beam is $30^{\circ}$.

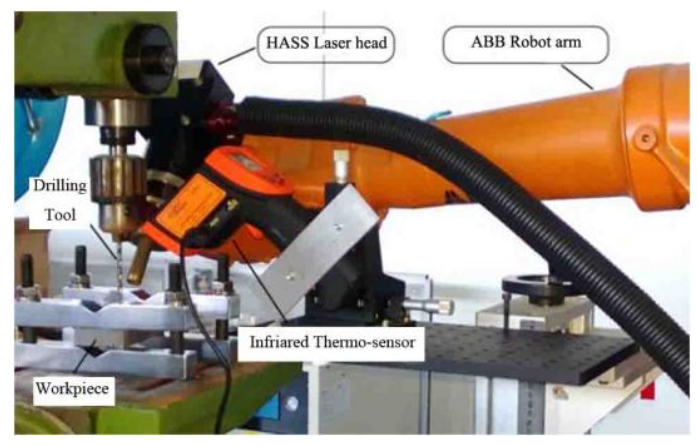

Fig.2 Experiment device of laser assisted drilling

The work-piece is fixed on the drilling machine's work platform, and a constant axial load is applied to the drill. The process is evaluated under different process conditions using two characteristics: (1) drilling holes diameter, and (2) drilling time. During drilling the laser power is kept as $200 \mathrm{~W}$ and drilling machine rotate speed is $235 \mathrm{r} / \mathrm{min}$. The laser beam 
diameter, laser heating time, loading force, and materials are variables.

\section{RESULTS AND DISCUSSIONS}

\subsection{Effects of processing parameters on the drilling holes diameter}

\subsubsection{Effects of heating time on the drilling hole diameter}

The drilling tool apex angle is $118^{\circ}$, so we can measure the drill hole's diameter $\emptyset d$, and then calculate the drill deep $h$. The relation is shown in Fig.3 At following research, we abide the rule that the bigger diameter is, the deeper hole is, and the more efficiency is.

Fig.4 shows the change in drilling hole diameter for laser heating times between 0 and 20 seconds for stainless steel, a laser power of $200 \mathrm{~W}$, a beam diameter of $3 \mathrm{~mm}$, and an angle of incidence $30^{\circ}$, axial load is $18 \mathrm{~N}$. The experiment shows that the drilling hole diameter increases from about $1 \mathrm{~mm}$ to $2 \mathrm{~mm}$ while increasing heating time.

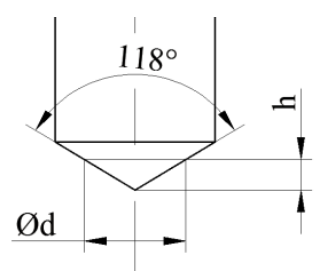

Fig.3 Drilling tool's geometry dimension

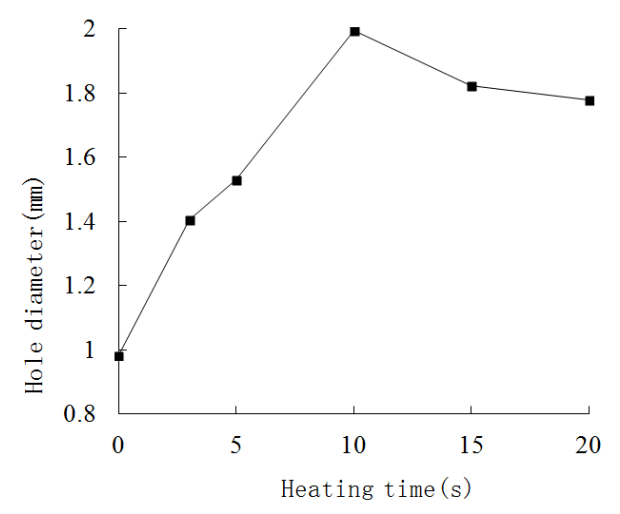

Fig.4 Hole diameter change with laser heating time

We test the temperature by infrared thermosensor, but the infrared thermo-sensor is test the average temperature of a zone, and the laser beam is abide Gaussian distribution, so we can't test the temperature accurately, the tested temperature is lower than we expect. However, the temperature variation trend may have inference value, the temperature of heating part is raise quickly at the beginning, and then increase slowly approximately 10 degree centigrade per second. As we all known, the work-piece below $\mathrm{Ac}_{1}$, tempering, the workpiece is soften; whereas higher than $\mathrm{Ac}_{1}$, and the surrounding temperature still low, so it could cooling down rapidly, it may be quenched, so the work-piece is harden [16]. Therefore, heating time is importance to laser assisted drilling.

\subsubsection{Effects of laser beam diameter on the drilling hole}

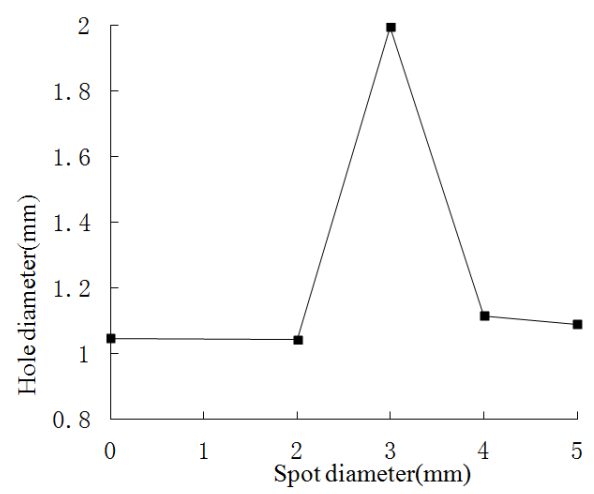

Fig.5 Relationship between hole diameter and laser spot diameter

As the laser power is constant, the laser beam diameter determine the power density of the incident light and thus temperature distribution over time. Fig.5 represents the results for stainless steel, a laser power of $200 \mathrm{~W}$, a heating time of $10 \mathrm{~s}$, a drilling time of $10 \mathrm{~s}$, and an angle of incidence $30^{\circ}$. From the fig. 5 shown that while laser beam is $3 \mathrm{~mm}$ the hole diameter is best. While the laser beam is $2 \mathrm{~mm}$, the laser power density is very high and the temperature higher than $\mathrm{AC}_{1}$, and temperature gradient is large, so the work-piece maybe oxidizing or quenching; while the laser beam is 4 or $5 \mathrm{~mm}$, the laser power density is low, and the temperature is low than tempering temperature.

\subsubsection{Effects of axial load on the drilling time}

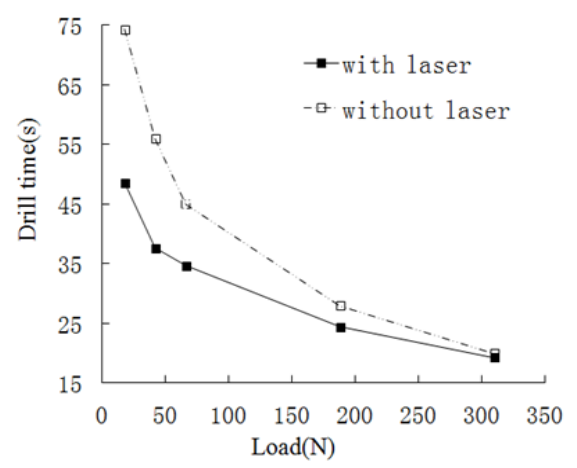

Fig.6 Relationship between drilling time and applied load

The drilling time means the time of drilling through a $5 \mathrm{~mm}$ thickness tube, Fig.6 shows the observed drilling time for different axial loads, using stainless steel tube, dimensions are $\varnothing 40 \times 5 \times 200 \mathrm{~mm}$, with laser is a laser power of $200 \mathrm{~W}$, a spot diameter of $3 \mathrm{~mm}$, and $10 \mathrm{~s}$ heating time. As expected the drilling time shortens as the axial load is increased. Using a laser spot to soften the material has a bigger 
effect on drilling time at lower axial loads than for higher axial loads. It's obviously the larger the load is, the more shorten drilling tome is, however, if the load is too large, it will destroy the tool easy, and the hole quality badly, and considering the individual error in the experiment, we need a large drilling time to minimum the relative error. So we should choose a small load to take this experiment, and choose the load is $18 \mathrm{~N}$.

For axial loads below 200N, with laser assisted drilling consuming about $65 \%-87 \%$ time of conventional drilling at the same axial loads. This indicates that tool life can be extended under these conditions. Hole dimensions accuracy should also improve as less axial load will also lead to less deformation (bending) of the drilling tool.

With high axial loads, the advantage of laser assistance seems to disappear, probably because the speed of material removal is preventing efficient heat transfer from the laser source.

\subsection{Comparison of laser assistance for different materials}

\subsubsection{Drilling hole diameter for different materials}

The experimental results of laser assisted drilling three materials are shown in Fig.7.Table 1 shows a comparison of drilling hole diameters of stainless steel, 45 steel and 40Cr respectively for conventional drilling and laser assisted drilling. The experimental parameters are laser power $200 \mathrm{~W}$, spot diameter $3 \mathrm{~mm}$, heating time $=10 \mathrm{~s}$, drilling time $=10 \mathrm{~s}$, angle of incidence $30^{\circ}$, axial load $=18 \mathrm{~N}$. For all materials, laser assistance can increase the hole diameter by at least $75 \%$.

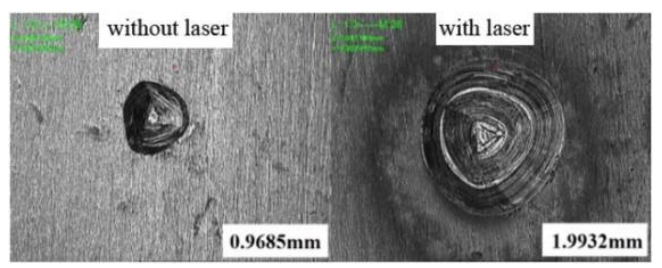

(a) stainless steel

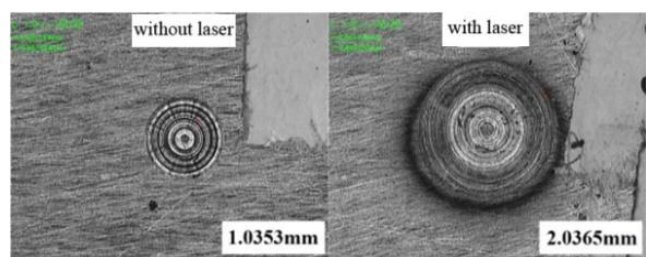

(b) 45 steel

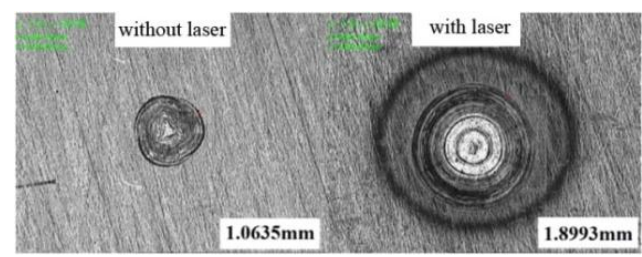

(c) $40 \mathrm{Cr}$ steel

Fig.7 Experimental results of three materials by laser assisted drilling
Table 1 Comparison of the hole diameter with laser and without laser heating in stainless steel, 45\# and 40Cr

\begin{tabular}{|c|c|c|c|}
\hline \multirow{2}{*}{ Result } & Without laser & \multicolumn{2}{|c|}{ With laser } \\
\cline { 2 - 4 } & Diameter/mm & Diameter/mm & Increasing rate /\% \\
\hline $\begin{array}{c}\text { Stainless } \\
\text { steel }\end{array}$ & 0.9685 & 1.9932 & 105.8 \\
\hline 45 steel & 1.0353 & 2.0365 & 96.7 \\
\hline $40 \mathrm{Cr}$ steel & 1.0635 & 1.8993 & 78.6 \\
\hline
\end{tabular}

\subsubsection{Drilling time for different materials}

Table 2 shows average drilling times for different materials with and without laser heating, for the case of drilling through a $5 \mathrm{~mm}$ thick tube. In all three materials, drilling times with laser preheating are shorter than without laser assistance. However, the effect is more pronounced for stainless steel (reduction by approx. 30\%) than for $45 \#$ steel or QT600 (drilling time reduction only around 12\%). (laser power $200 \mathrm{~W}$, spot diameter $3 \mathrm{~mm}$, heating time $=10 \mathrm{~s}$, drilling time $=10 \mathrm{~s}$, angle of incidence $30^{\circ}$, axial load $=18 \mathrm{~N}$ )

Table 2 Comparison of drilling time with and without laser heating

\begin{tabular}{|c|c|c|c|}
\hline \multirow{2}{*}{ Material } & \multirow{2}{*}{$\begin{array}{l}\text { Without laser } \\
\text { Drilling time/s }\end{array}$} & \multicolumn{2}{|l|}{ With laser } \\
\hline & & Drilling time/s & $\begin{array}{l}\text { Decreasing } \\
\text { rate } 1 \%\end{array}$ \\
\hline $\begin{array}{l}\text { Stainless } \\
\text { steel }\end{array}$ & 74.3 & 48.6 & 34.6 \\
\hline $45 \#$ steel & 56.5 & 49.9 & 11.7 \\
\hline QT600 & 72.3 & 63.2 & 12.6 \\
\hline
\end{tabular}

\section{CONCLUSION}

In this paper, the parameters of laser assisted drilling by means of an experimental study with stainless steel, 45\# steel, 40Cr, and QT600 respectively are proposed. Conclusions are as follows:

(1) In using $200 \mathrm{~W}$ power laser preheating assisted drilling, as for 45 steel the optimum parameters are laser beam of $3 \mathrm{~mm}$, heating time of $10 \mathrm{~s}$ and axial drilling force of $18 \mathrm{~N}$.

(2) With laser assisted drilling, the drilling hole diameter for all materials is in the range of $75-100 \%$ larger than without laser for all materials, which suggests the feasibility to assist drilling with laser surface softening in the early stage of drilling.

(3) With laser assisted drilling, the drilling time for stainless steel are about $30 \%$ shorter than with conventional drilling. For 45 and QT600, the reduction of drilling time appears to be less pronounced but it is left to future research to investigate the suitable processing parameters for these materials. 


\section{ACKNOWLEDGEMENT}

This work is supported by the National Natural Science Foundation of People's Republic of China (Grant No. 51307170) and Innovation Project of Nansha District, Guangzhou, People's Republic of China (Grant No. 201201020). The authors gratefully acknowledge the help of Precision Engineering Research Center, Guangzhou Institute of Advanced Technology, Chinese Academy of Sciences.

\section{REFERENCES}

[1] Yao Yuan. "Application of laser processing technology in automobile industry both interiorly and abroad". Machinist Metal Forming. pp. 24-26, 2008.

[2] C.R. Dandekar, Y.C. Shin, "Experimental evaluation of laser-assisted machining of silicon carbide particlereinforced aluminum matrix composites", Int J Adv Manuf Tech, Vol.66, pp.1603-1610, 2013.

[3] H.T. Ding, Y.C. Shin, "Laser-assisted machining of hardened steel parts with surface integrity analysis", Int J Mach Tool Manu, Vol.50, pp.106-114, 2010.

[4] P.A. Rebro, Y.C. Shin, F.P. Incropera, "Design of operating conditions for crackfree laser-assisted machining of mullite", Int J Mach Tool Manu, Vol.44, pp. 677-694, 2004.

[5] S. Skvarenina, Y.C. Shin, "Laser-assisted machining of compacted graphite iron", Int J Mach Tool Manu, Vol.46, pp.7-17, 2006.
[6] Y.G. Tian, Y.C. Shin, "Laser-assisted burnishing of metals", Int J Mach Tool Manu, Vol.47, pp.14-22, 2007.

[7] Y. Jeon, C.M. Lee, "Current Research Trend on Laser Assisted Machining", Int J Precis Eng Man, Vol.13, pp.311-317, 2012.

[8] D.H. Kim, C.M. Lee, "Development of a one-axis manipulator for laser-assisted machining", J Cent South Univ, Vol.20, pp. 378-384, 2013.

[9] K.S. Kim, C.M. Lee, "Prediction of preheating conditions for inclined laser assisted machining", J Cent South Univ, Vol19, pp.3079-3083,2012.

[10] B. Yang, X. Shen, S. Lei, "Mechanisms of edge chipping in laser-assisted milling of silicon nitride ceramics", Int J Mach Tool Manu, Vol 49, pp. 344-350, 2009.

[11] Information on www.ipt.fraunhofer.de \& www.ilt.fraunhofer.delen.html.

[12] Wang Hui-yi, Li Cong-xin, Ruan Xue-yu. "3-D simulation of the temperature field of laser assisted machining with FEM". J. SHANGHAI JIAOTONG UNIV. No.1, pp.98$101,2001$.

[13] Wu Jian. "Mechanism of metal's laser transformation hardening and optimum of laser technical parameters". Hot working technology. Vol7, pp.57-59, 2004.

[14] YAN Cuo, LI Li-jun, JIN Xiang-zhong, LIU Ji-chang, CHEN Pei. "Temperature field distribution and cutting depth during laser-assisted machining of hot-sintered Al2O3 ceramics". The Chinese Journal of Nonferrous Metals.Vol18, pp. 254-259, 2008.

[15] T.-C. Jen, Y.-M. Chen, F. Tuchowski, "Experimental and Numerical Studies of Laser-Assisted Drilling Processes", in: ASME 2004 Heat Transfer/Fluids Engineering Summer Conference, American Society of Mechanical Engineers, pp. 1015-1023, 2004.

[16] C.X. SHEN Chaoying, "Application of Laser Quenching in Overhaul of Engine Crank-shaft", Hot working technology, Vol18, pp. 200-201, 2001. 